\title{
Synthesis and adhesive property study of polyoxetanes grafted with catechols via $\mathrm{Cu}(\mathrm{I})$-catalyzed click chemistry
}

\author{
Mingchen Jia ${ }^{\mathrm{a}, \mathrm{b}}$, Ailei $\mathrm{Li}^{\mathrm{a}, \mathrm{b}}$, Youbing $\mathrm{Mu}^{\mathrm{a}, *}$, Wei Jiang ${ }^{\mathrm{c}}$, Xiaobo Wan ${ }^{\mathrm{a}, *}$ \\ ${ }^{a}$ Key Laboratory of Biobased Materials, Qingdao Institute of Bioenergy and Bioprocess Technology, Chinese Academy of Sciences, 189 Songling Road, \\ Qingdao, Shandong Province 266101, PR China \\ ${ }^{\mathrm{b}}$ University of Chinese Academy of Sciences, 19A Yuquan Road, Beijing 100049, PR China \\ ${ }^{\mathrm{c}}$ National Engineering Research Center for Organic Pollution Control and Resource Reuse, State Key Laboratory of Pollution and Resource Reuse, \\ School of the Environment, Nanjing University, 22 Hankou Road,Nanjing, Jiangsu Province 210093, PR China
}

\section{A R T I C L E I N F O}

\section{Article history:}

Received 22 October 2013

Received in revised form

10 January 2014

Accepted 22 January 2014

Available online 31 January 2014

\section{Keywords:}

Mussel-inspired adhesive

Polyoxetane

Click chemistry

\begin{abstract}
A B S T R A C T
Mussel-inspired catechol-containing polymers have drawn great attention due to their outstanding adhesive properties. Catechol-containing polyethylene glycol (cPEG) is a well-studied catechol-containing polymer used for tissue repair. Nevertheless, catechols can only be attached to the chain ends of polyethylene glycols thus the bonding strength of the resulting polymers is limited. Aiming at solving the problem, a series of clickable polyoxetane copolymers with grafted catechol moieties were synthesized in an efficient manner. Upon addition of $\mathrm{FeCl}_{3}$ as the cross-linker, strong bonding strength of the adhesive was achieved. Polymer containing 15.5 molar percent of catechol showed the strongest bonding strength up to $5.59 \mathrm{MPa}$ on sanded stainless steel. It was found that the triazole groups also contributed to the overall adhesive performance. This polyoxetane-based adhesive also displayed strong bonding ability to a variety of other substrates including porcine skin.
\end{abstract}

(c) 2014 Elsevier Ltd. All rights reserved.

\section{Introduction}

The catechol-containing polyethylene glycol (cPEG) has found its application in tissue repairing due to its biocompatibility and underwater bonding ability. The inspiration comes from a marine mollusk named blue mussel which uses catechol-containing proteins to stick on rocks and ship hulls [1-3]. Lee et al. reported the preparation of a series of catechol-containing PEGs and studied their gelation behavior in the presence of oxidizing agents. They demonstrated that the PEGs containing more than one catechol can undergo oxidative polymerization to form polymeric network [4]. Then Burke et al. used the four-arm PEG with a catechol moiety attached to each end for tissue adhesion study. This adhesive formed strong bonding on porcine skin (35.1 kPa) when being oxidized at $37{ }^{\circ} \mathrm{C}$, which was several times stronger than a fibrin glue control [5]. Brubaker et al. further interrogated the in-vivo performance of cPEG in a murine model of islet transplantation, in which cPEG was mixed with sodium periodate to efficiently immobilize transplanted islets and minimize inflammatory response [6]. Although PEG-based adhesives were studied in-

\footnotetext{
* Corresponding authors.

E-mail addresses: muyb@qibebt.ac.cn (Y.Mu),wanxb@qibebt.ac.cn, wanxiaob@ sas.upenn.edu (X. Wan).
}

depth, an obvious shortcoming of PEG is that the polymer can only be modified at its chain ends. The highest catechol content of cPEG used for adhesive was only about $1.7 \mathrm{~mol} \%$ when four catechols were attached to a 4-arm PEG (10 kDa). However, the molar percent of catechol moiety in mussel foot protein ( $\mathrm{mfp}$ ) can be as high as 30\% [7]. As a result, the strength of the bond formed by cPEG is limited. There is still a need for stronger tissue adhesives, especially in the case of bone repairing and moving organs bonding.

Oxetanes can undergo ring-opening polymerization to generate polyoxetanes, which have similar polyether backbone as PEG but with modifiable side chains. Feng and co-workers synthesized homo- and copolymers from 3-(2-cyanoethoxy) methyl- and 3(methoxy (triethylenoxy)) methyl-3'-methyloxetane through cationic ring-opening polymerization. These polyoxetanes have low $T_{\mathrm{g}}\left(-27^{\circ} \mathrm{C}\right.$ to $\left.-47^{\circ} \mathrm{C}\right)$ and high heat decomposition temperature (about $300{ }^{\circ} \mathrm{C}$ ) [8]. Wynne and co-workers employed copolymers of $3,3^{\prime}$-substituted oxetanes as the soft blocks in polyurethanes to produce various functional polyurethanes [9-11]. Polyoxetane is also considered to be biocompatible like PEG but more versatile. Recently, Yang and co-workers developed a new platform for drug delivery based on clickable polyoxetanes. PEGs were grafted onto the backbone of polyoxetanes via $\mathrm{Cu}(\mathrm{I})$-catalyzed alkyne-azide cycloaddition click chemistry (CuAAC) to improve its water-solubility. Anti-cancer drugs, fluorescent agents and other functional groups were clicked onto the backbone in an efficient 
manner. In cytotoxicity assessment study, the PEG-grafted polyoxetanes are compatible with human dermal fibroblasts at concentrations up to $2 \mathrm{mg} / \mathrm{l}[12,13]$. Inspired by the work mentioned above, we envisioned that a catechol-containing polyoxetane might be an adjustable platform for alternative adhesive polymers to cPEG.

Taking advantage of the efficiency of click chemistry, various amounts of catechols can be graft onto the backbone of a polymer without lowering the degree of polymerization. However, click chemistry is seldom used in the literature to synthesize catecholcontaining polymers. Hawker and coworkers introduced catechols to polysiloxanes via thiol-ene click chemistry. The loading of catechols in the polysiloxanes ranged from $0 \mathrm{~mol} \%$ to $50 \mathrm{~mol} \%$, in good consistency with the catechol feeding ratio [14]. Müller and coworkers utilized an alkyne-modified catechol-derivative to functionalize $\mathrm{Fe}_{3} \mathrm{O}_{4}$ nanoparticles. Azido-end group functionalized PEGs were then grafted onto the functionalized nanoparticles via CuAAC [15]. Moreover, triazoles formed in CuAAC are chemically and biochemically invisible, ensuring the stability and biocompatibility of the adhesive polymers under conditions where they are used [16].

As far as we know, there has not been any report on the synthesis of catechol-containing polyoxetanes via CuAAC. We herein wish to report the synthesis of catechol-containing polyoxetane and its adhesive properties under dry conditions. The new adhesive showed strong bonding strength on varies substrates, and we believe that further modification on this novel platform (such as to increase its solubility in aqueous solution and to lower its polydispersity) will lead to stronger tissue adhesives.

\section{Experimental section}

\subsection{Materials and methods}

All the starting materials were purchased from SigmaAldrich and used as received unless otherwise stated. Substrates for lap shear test were purchased from the local stores. $\mathrm{BF}_{3} \cdot \mathrm{Et}_{2} \mathrm{O}$ was fresh distilled under reduced pressure before use. THF and $\mathrm{CH}_{2} \mathrm{Cl}_{2}$ were dried and distilled before use. 3-ethyl-3methoxymethyl-oxetane (EMOMO) and 3-ethyl-3propargyloxymethyl-oxetane (EPOMO) were synthesized according to an article with modifications (Supplementary Information, Scheme S1) [17], which were distilled over $\mathrm{CaH}_{2}$ before use. ${ }^{1} \mathrm{H}$ NMR and ${ }^{13} \mathrm{C}$ NMR spectra were recorded on a Bruker AV600 using tetramethylsilane (TMS) as an internal standard. Gel permeation chromatography (GPC) data were obtained on a Polymer Laboratories PL-GPC 120 system equipped with a refractive index detector. A combination of two polystyrene gel columns of PL gel-MIXED C was used, with tetrahydrofuran as an eluent at a flow rate of $1.0 \mathrm{~mL} / \mathrm{min}$ and a temperature of $40{ }^{\circ} \mathrm{C}$. The columns were calibrated using polystyrene standards. Lap shear test was conducted on a TY-8000 universal materials testing system equipped with a $5000 \mathrm{~N}$ load cell.

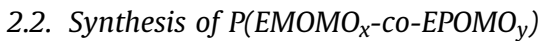

The polyoxetanes with various content of EPOMO were synthesized by adjusting the feeding ratio of the two monomers. The polymerization was carried out according to a reported procedure with slight modifications [8]. For example, the copolymer with the EMOMO:EPOMO feeding ratio at 4:1:was synthesized using the following method: To $2 \mathrm{~mL}$ of $\mathrm{CH}_{2} \mathrm{Cl}_{2}$ in a $50 \mathrm{~mL}$ two-neck flask equipped with a $50 \mathrm{~mL}$ addition funnel under argon atmosphere, were added $\mathrm{BF}_{3} \cdot \mathrm{Et}_{2} \mathrm{O}(63.1 \mu \mathrm{L}, 0.5 \mathrm{mmol})$ and ethylene glycol $(13.9 \mu \mathrm{L}, 0.25 \mathrm{mmol})$ at $0{ }^{\circ} \mathrm{C}$. After $20 \mathrm{~min}$, a mixture of EMOMO
(5.21 g, $0.04 \mathrm{~mol}$ ) and EPOMO (1.54 g, $0.01 \mathrm{~mol})$ in $3 \mathrm{~mL}$ of $\mathrm{CH}_{2} \mathrm{Cl}_{2}$ was added dropwise through the addition funnel into the solution in an hour. The mixture was stirred at $0{ }^{\circ} \mathrm{C}$ for another $5 \mathrm{~h}$. Water $(10 \mathrm{~mL})$ was then added to terminate the polymerization. The product was extracted with $\mathrm{CH}_{2} \mathrm{Cl}_{2}(2 \times 30 \mathrm{~mL})$ and washed with brine $(2 \times 30 \mathrm{~mL})$. The $\mathrm{CH}_{2} \mathrm{Cl}_{2}$ layer was concentrated and the residue was added drop-wise into $200 \mathrm{~mL}$ of methanol under stirring. The precipitate was dissolved in $\mathrm{CH}_{2} \mathrm{Cl}_{2}(20 \mathrm{~mL})$, concentrated and precipitated out again in methanol $(200 \mathrm{~mL})$. The precipitate was dried under reduced pressure to afford the copolymer (5.56 g) as a solid. Yield: $66.8 \%$.

\subsection{Synthesis of 3,4-bis-(tert-butyl-dimethyl-silanyloxy)-benzyl azide}

3,4-Bis-(tert-butyl-dimethyl-silanyloxy)-benzyl bromide was synthesized according to the method developed by Nicolaou (Supplementary Information, Scheme S2) [18]. Sodium azide (4.38 g, $0.067 \mathrm{~mol}$ ) was added to a stirred solution of 3,4-bis(tert-butyl-dimethyl-silanyloxy)-benzyl bromide $(14.60 \mathrm{~g}$, $0.034 \mathrm{~mol}$ ) in acetone and the resulting mixture was heated at reflux for $8 \mathrm{~h}$. Water $(20 \mathrm{~mL})$ was then added to the reaction mixture and acetone was evaporated. The resulting mixture was extracted with $\mathrm{CH}_{2} \mathrm{Cl}_{2}(2 \times 100 \mathrm{~mL})$ and the extract was washed with water $(100 \mathrm{~mL})$ and brine $(100 \mathrm{~mL})$, dried over anhydrous $\mathrm{MgSO}_{4}$ and concentrated. The crude product was subjected to silica column chromatography (petroleum ether $/ \mathrm{CH}_{2} \mathrm{Cl}_{2}$ : $20 / 1$ $\mathrm{v} / \mathrm{v}$ ) to afford the benzyl azide ( $12.00 \mathrm{~g})$ as a colorless oil. Yield: 93\%. ${ }^{1} \mathrm{H} \mathrm{NMR}\left(\mathrm{CDCl}_{3}, 600 \mathrm{MHz}\right): \delta(\mathrm{ppm}) 0.20(\mathrm{~s}, 6 \mathrm{H}), 0.21(\mathrm{~s}, 6 \mathrm{H})$, 0.99 (s, 9H), 0.10 (s, 9H), 4.19 (s, 2H), 6.75-6.83 (m, 3H) (Supplementary Information, Fig. S3). ${ }^{13} \mathrm{C} \mathrm{NMR}\left(\mathrm{CDCl}_{3}, 300 \mathrm{MHz}\right)$ : $\delta(\mathrm{ppm})$ 147.2, 147.1, 128.4, 121.2, 121.3, 121.2, 54.5, 25.9, 18.47, 18.45 (Supplementary Information, Fig. S4).

\subsection{Synthesis of protected catechol grafted (PCG)-P(EMOMO ${ }_{x}^{-C O}$ $\mathrm{EPOMO}_{y}$ )}

Using the polyoxetane obtained at the feeding ratio of $4: 1$ (EMOMO:EPOMO) as an example: 3,4-bis-(tert-butyl-dimethylsilanyloxy)-benzyl azide ( $1.3 \mathrm{~g}, 3.3 \mathrm{mmol}), \mathrm{CuSO}_{4} \cdot 5 \mathrm{H}_{2} \mathrm{O}(54.9 \mathrm{mg}$, $0.22 \mathrm{mmol})$, ascorbic acid (77.5 $\mathrm{mg}, 0.44 \mathrm{mmol}$ ) were added to a solution of copolymer $(1.5 \mathrm{~g}, 0.09 \mathrm{mmol})$ in $20 \mathrm{~mL}$ of THF. The resulting mixture was heated at reflux overnight under argon atmosphere. THF was evaporated and to the residue was added $50 \mathrm{~mL}$ of $\mathrm{CH}_{2} \mathrm{Cl}_{2}$. The resulting mixture was washed with water $(50 \mathrm{~mL})$ and brine $(3 \times 50 \mathrm{~mL})$. The aqueous layer was extracted with $\mathrm{CH}_{2} \mathrm{Cl}_{2}$ $(3 \times 50 \mathrm{~mL})$. The combined $\mathrm{CH}_{2} \mathrm{Cl}_{2}$ layer was concentrated and added drop-wise into $200 \mathrm{~mL}$ of methanol under stirring to precipitate the polymer. The crude product was purified by repeating precipitation. The precipitate was dried under vacuum to afford the PCG-P(EMOMO $\left.{ }_{84.5 \%-C o-E P O M O} 15.5 \%\right)$ as a viscous solid $(8.50 \mathrm{~g})$. Yield: $91.4 \%$.

\subsection{Synthesis of catechol-grafted (CG)-P(EMOMO ${ }_{x}-$ Co-EPOMO $\left._{y}\right)$}

In a general procedure, concentrated $\mathrm{HCl}$ ( 5 equiv. to catechol) was added to a solution of PCG-P(EMOMO $\left.{ }_{\mathrm{x}}-\mathrm{Co}-\mathrm{EPOMO}_{\mathrm{y}}\right)$ in THF $(0.25 \mathrm{~g} / \mathrm{mL})$ under argon atmosphere at room temperature. The resulting mixture was stirred at room temperature overnight. The resulting mixture was concentrated and added dropwise into $200 \mathrm{~mL}$ of $n$-hexane under stirring. The precipitate was dissolved in THF $(20 \mathrm{~mL})$, concentrated and precipitated out again in $n$-hexane $(200 \mathrm{~mL})$. The precipitate was dried under reduced pressure to afford the CG-P(EMOMO $\left.{ }_{\mathrm{x}}-\mathrm{CO}-\mathrm{EPOMO}_{\mathrm{y}}\right)$ as a viscous solid $(5.50 \mathrm{~g})$. Yield: $91.0 \%$. 


\subsection{Adhesion experiments}

The substrates were cut into rectangular pieces with $10 \mathrm{~cm}$ long and $2.5 \mathrm{~cm}$ wide. Metal and plastic pieces were sanded with a 50grit sandpaper, cleaned, washed with water and ethanol and then dried. The poplar pieces were bonded without any pretreatment. The glass pieces were cleaned, washed with water and ethanol and dried. Two aluminum pieces were then bonded on the glass adherends using Krazy Glue before test. The porcine skin was washed with detergent and water, then air-dried, and bonded on the outside surface. In the adhesion process, $20 \mu \mathrm{L}$ of CG-P(EMO$\left.\mathrm{MO}_{\mathrm{x}}-\mathrm{Co}-\mathrm{EPOMO}_{\mathrm{y}}\right)$ solution in ethanol $(0.3 \mathrm{~g} / \mathrm{mL})$ was spread on two adherends with an area of $3 \mathrm{~cm}^{2}[2]$. Then $10 \mu \mathrm{L}$ of $\mathrm{FeCl}_{3}$ in ethanol was added on one of the adherends. The molar feeding ratio of $\mathrm{Fe}^{3+}$ to catechol was $1: 3$. The ends of the two adherends were overlapped after being dried by a blower. The two adherends were fastened by two binder clips and placed under room temperature for $1 \mathrm{~h}$. Then a load of $50 \mathrm{~N}$ was applied on the samples, and the samples were cured at $55^{\circ} \mathrm{C}$ for $22 \mathrm{~h}$ to evaporate the solvent and cross-link the adhesive polymers. Lap shear adhesion measurements were conducted on a universal materials testing system. Adherends were pulled apart at a rate of $10 \mathrm{~mm} / \mathrm{min}$. At least five samples were measured for each test and the average value of the bonding strength was adopted, with the error bar showing the maximum deviation of the measured data.

\section{Results and discussion}

\subsection{Synthesis of the adhesive polymer}

The synthetic route towards the catechol-containing polyoxetane is shown in Scheme 1. Two oxetane derivatives, EMOMO and EPOMO, were synthesized for copolymerization. EPOMO contains a clickable terminal alkynyl group that is suitable for postpolymerization modification. They are then copolymerized to give the corresponding polyoxetanes. Oxetanes with longer alkyl chain were also synthesized and tested for copolymerization, however, the degree of polymerization (DP) of the polymers obtained from such monomers was relatively low. EMOMO was then selected due to its relatively high reactivity in copolymerization, leading to copolymers with higher molecular weight.

EMOMO and EPOMO were copolymerized at different feeding ratios (9:1, 4:1, 7:3, 3:2 and 1:1 molar ratio) using $\mathrm{BF}_{3} \cdot \mathrm{Et}_{2} \mathrm{O}$ as the catalyst and ethylene glycol as the initiator. The polymerization was carried out at $0{ }^{\circ} \mathrm{C}$ to achieve fast polymerization rate and depress side reactions $[19,20]$. A typical ${ }^{1} \mathrm{H}$ NMR spectrum of the copolymer with the molar feeding ratio of $4: 1$ was shown in Fig. 1. As can be seen in the spectrum, the characteristic peaks of oxetane (Supplementary Information, Figs. S1-S2) disappeared, and the appearance of a singlet at $3.19 \mathrm{ppm}$ confirmed the occurrence of the polymerization. The peaks at $\sim 0.84$ and $1.38 \mathrm{ppm}$ ( $\mathrm{a}$ and $\mathrm{b}$ ) were assigned to the protons on ethyl groups from both monomers, since they shared similar chemical environment in the polymer chains. The signal at $3.23 \mathrm{ppm}$ (d) was assigned to the methylene group on the side chain of EMOMO moiety and the one at $3.38 \mathrm{ppm}$ (e) was assigned to that of EPOMO. The peak at $2.39 \mathrm{ppm}(\mathrm{h})$ was assigned to the acetylene proton and the peak at $4.09 \mathrm{ppm}(\mathrm{g})$ was assigned to the methylene protons adjacent to the alkynyl group. The incorporation ratio of EPOMO into the copolymer was calculated according to the integral ratio of peak $h$ to peak b. Generally, the incorporation ratio of EPOMO into the copolymer increased with the increase of its feeding ratio, but was slightly lower than the feeding ratio, as shown in Table 1, indicating the difference in the reactivity of the two monomers.

The molecular weights of the copolymers fell between $10 \mathrm{kDa}$ and $20 \mathrm{kDa}$ and decreased gradually as the content of EPOMO increased (Table 1). The molecular weights of the polyoxetanes were higher than PEGs used in mussel-inspired adhesive polymers (10 kDa), which implies that the adhesives based on polyoxetanes might show better adhesive properties, since polymeric adhesives sharing similar structures but with higher molecular weight usually form stronger bonds than those with lower one.

We noticed that the polydispersity index (PDI) of the polyoxetanes is around 2.0, which is larger than the PDI of PEG (approx. 1.00). As biomedical applications generally need polymers with low PDI, the PDI of polyoxetanes at this stage might not be suitable for
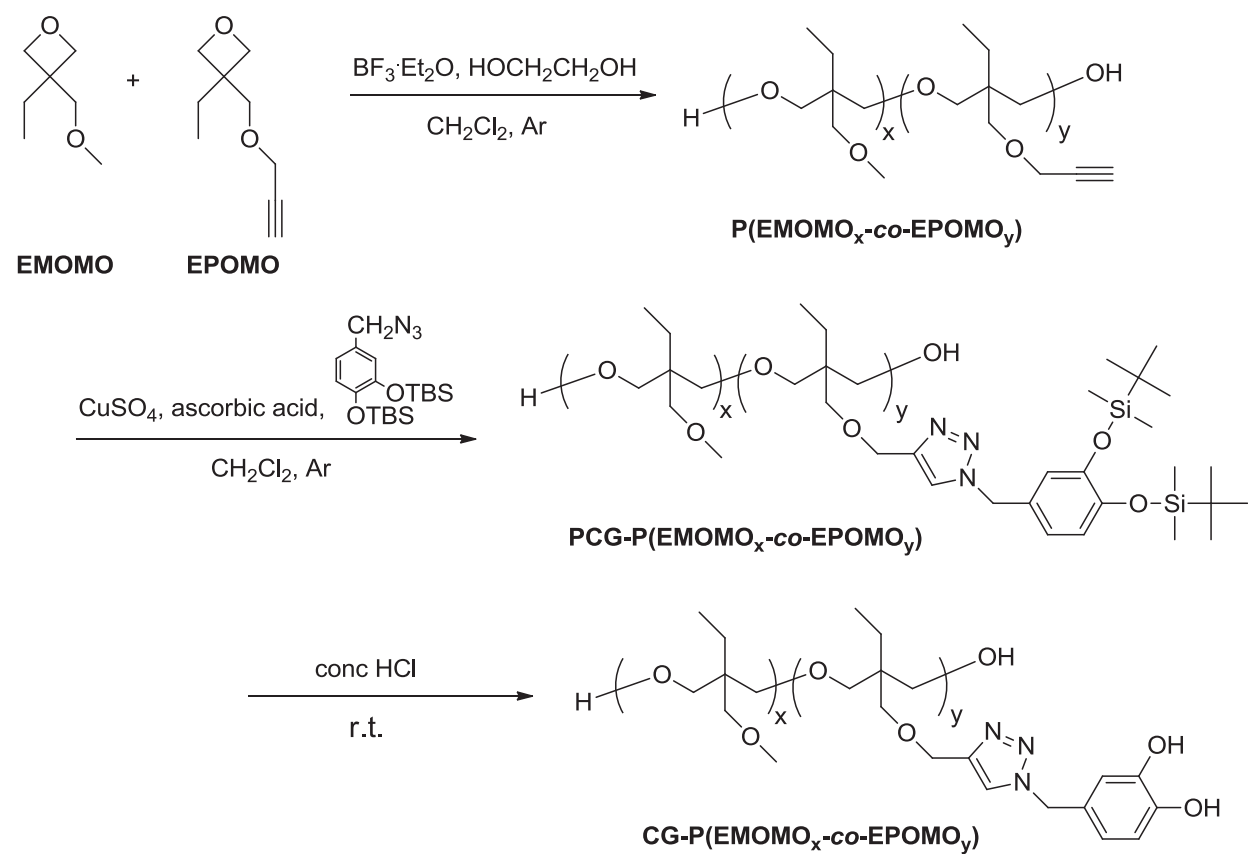

Scheme 1. Synthetic route to catechol-containing polyoxetane adhesive polymer. 


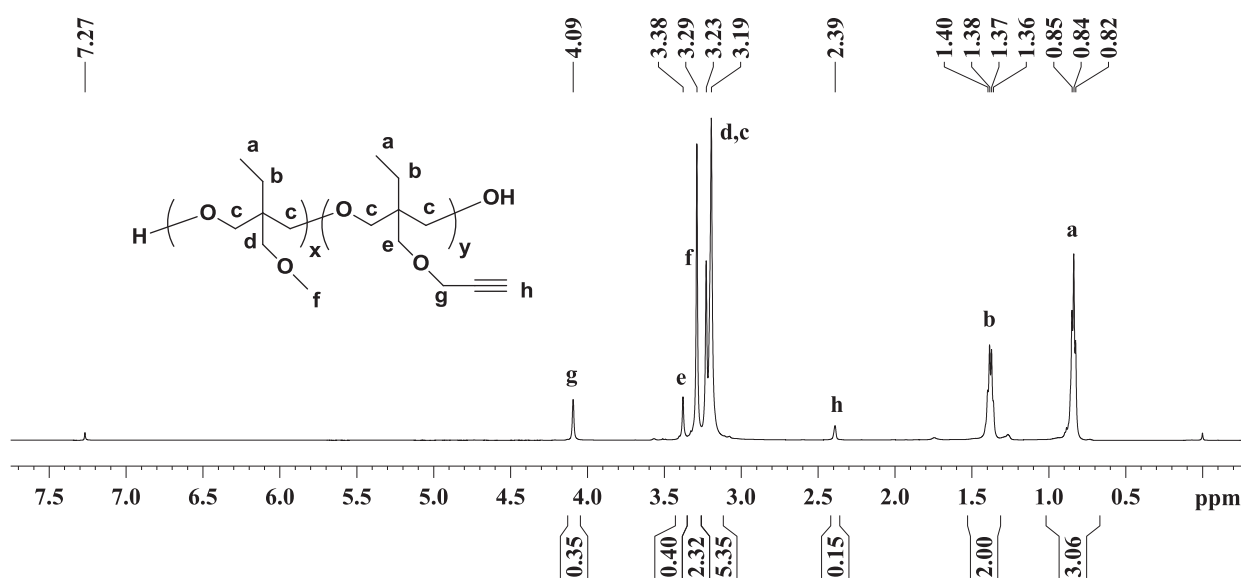

Fig. 1. ${ }^{1} \mathrm{H}$ NMR of the copolymer of EMOMO and EPOMO in $\mathrm{CDCl}_{3}$ at the molar feeding ratio of 4:1.

direct biomedical use. However, if controlled ring-opening polymerization methods are used, polyoxetanes with relatively low PDIs can be obtained. Till to date, only the controlled coordinate polymerization of unsubstituted oxetane is reported. Aida and coworkers reported the living anionic polymerization of oxetane in the presence of bulky organoaluminum diphenolates and onium salts. The PDI of the resulting polyoxetanes were around 1.10 when the molecular weights were below $20 \mathrm{kDa}$ [21]. The controlled polymerization of substituted oxetanes will be helpful to meet the requirement of biomedical applications and is our next goal.

\subsection{Post-polymerization modification to introduce catechol moiety}

Nevertheless, catechol moiety was grafted onto the polyoxetane with broad PDI to test its adhesive properties. TBS (tert-butyldimethylsilyl) group protected catechols with an azide group were synthesized in high yield and the method is readily scalable. It was then grafted onto the polyoxetane backbone via CuAAC chemistry.

$\mathrm{CuSO}_{4} \cdot 5 \mathrm{H}_{2} \mathrm{O}$ and ascorbic acid were chosen to form cuprous ion in situ as the catalysts for the graft reaction, which could be easily removed by washing the obtained polymer with abundant water and repeating precipitation. Successful grafting was verified in the ${ }^{1}$ H NMR spectrum (Fig. 2, Supplementary Information, Figs. S6-S9). The peak of the acetylene proton disappeared completely and a new peak at $7.37 \mathrm{ppm}$ appeared, which was assigned to the proton on the triazole group $(\mathrm{h})$. The peak of methylene protons adjacent to the triazole group was located at $4.55 \mathrm{ppm}$. The peak i was assigned to the methylene protons adjacent to the benzene ring. The peaks at $\sim 6.70 \mathrm{ppm}(\mathrm{j})$ and the peaks characteristic of TBS $(\mathrm{k}$, $\left.k^{\prime}, 1, l^{\prime}\right)$ were assigned to the protons of TBS-protected catechol. The peaks of the other protons showed little change. The ratio between the integral value of peak $i$ and peak $b$ was calculated to determine the molar percent of protected catechol attached to the polyoxetane. The molar percent of protected catechol in the copolymers inferred from ${ }^{1} \mathrm{H}$ NMR was $4.5 \%, 15.5 \%, 24 \%, 31 \%$ and $46 \%$ respectively, which is in accordance with the EPOMO content in the copolymer, indicating a full conversion of the alkynyl groups.

The TBS groups on catechols were easily removed using concentrated $\mathrm{HCl}$. As can be seen from ${ }^{1} \mathrm{H}$ NMR spectrum of the final adhesive polymer (Fig. 3), characteristic peaks of TBS groups disappeared and the other peaks showed little change. Considering that the ether bonds in the polymer may be sensitive to acid, we also treated the unmodified polyoxetane copolymer with $\mathrm{HCl}$ under the same conditions to test the stability of the backbone. GPC results of the polyoxetane before and after acid treatment did not show any noticeable evidence of degradation. So the ether bonds in the polyoxetanes are stable during the deprotection process. Thus, the influence of the acid treatment on the molecular weight of the final polymer could be ruled out.

Since free-catechol containing polymers might adhere to the column to make GPC results unauthentic [22], the molecular weights of the final catechol-containing polyoxetanes were estimated from the GPC results of the unmodified polyoxetanes. As can be seen from the results, the five adhesive polymers have similar molecular weights $\left(\sim 19 \mathrm{kDa}\right.$ for $\left.M_{\mathrm{n}}\right)$. CG-P(EMOMO ${ }_{95.5 \%-C O}$ $\left.\mathrm{EPOMO}_{4.5 \%}\right)$ and $\mathrm{CG}-\mathrm{P}\left(\mathrm{EMOMO}_{54 \%}\right.$-Co-EPOMO $\left.46 \%\right)$ have a slightly higher molecular weight than the other three polymers (Supplementary Information, Table S1).

\subsection{Characterization of the adhesive properties}

In mussel adhesives, there is an unusually high content of transition metal ions which are involved in the curing of the adhesive proteins. Wilker and coworkers found that, among all the transition metal ions presented in mussel adhesives, $\mathrm{Fe}^{3+}$ plays the most important role in cross-linking, in which $\mathrm{Fe}^{3+}$ ions act as the metal center for complexation and the oxidant for covalently crosslinking [23]. So in our experiments, $\mathrm{FeCl}_{3}$ was used as the cross-

Table 1

Characterization data for $\mathrm{P}\left(\mathrm{EMOMO}_{\mathrm{x}}-\mathrm{CO}-\mathrm{EPOMO}_{\mathrm{y}}\right)$ copolymers.

\begin{tabular}{|c|c|c|c|c|c|c|c|c|}
\hline \multicolumn{2}{|c|}{ Feeding ratio(\%) } & \multicolumn{2}{|c|}{ Polymer composition(\%) } & \multirow[t]{2}{*}{$M_{\mathrm{n}}(\mathrm{KDa})$} & \multirow[t]{2}{*}{$M_{\mathrm{w}}(\mathrm{KDa})$} & \multirow[t]{2}{*}{ PDI } & \multirow[t]{2}{*}{ Monomer conversion (\%) } & \multirow[t]{2}{*}{ Yield (\%) } \\
\hline EMOMO & EPOMO & EMOMO & ЕРОМО & & & & & \\
\hline 90 & 10 & 95.5 & 4.5 & 19.9 & 38.9 & 2.0 & 96.1 & 64.9 \\
\hline 80 & 20 & 84.5 & 15.5 & 16.5 & 37.1 & 2.2 & 98.3 & 66.8 \\
\hline 70 & 30 & 76 & 24 & 15.5 & 31.3 & 2.1 & 97.8 & 59.7 \\
\hline 60 & 40 & 69 & 31 & 13.7 & 32.0 & 2.3 & 90.3 & 44.3 \\
\hline 50 & 50 & 54 & 46 & 14.4 & 31.7 & 2.2 & 93.9 & 45.0 \\
\hline
\end{tabular}




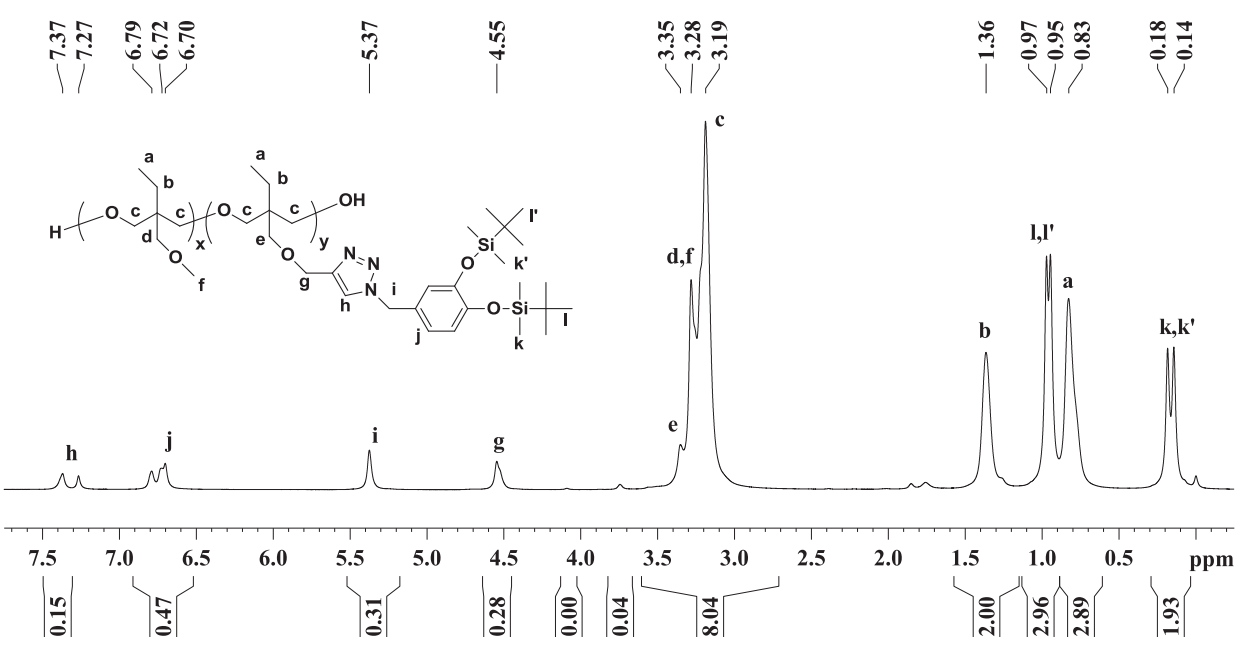

Fig. 2. ${ }^{1} \mathrm{H}$ NMR of PCG-P(EMOMO $\left.{ }_{84.5 \%}-\mathrm{Co}-\mathrm{EPOMO}_{15.5 \%}\right)$ in $\mathrm{CDCl}_{3}$.

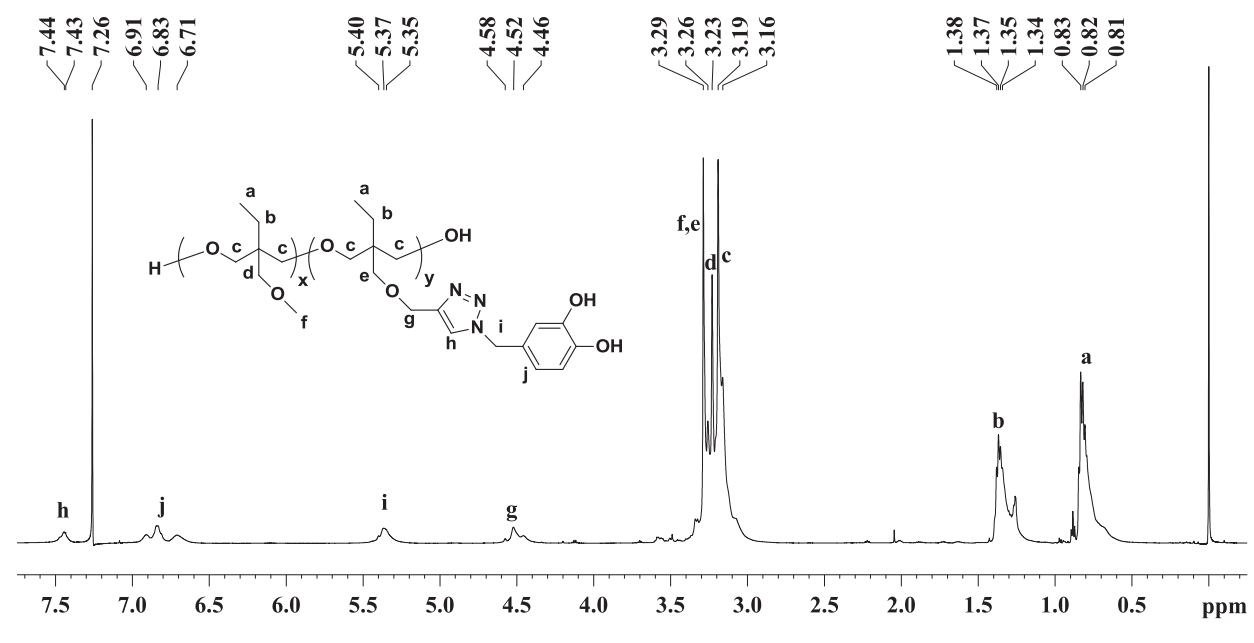

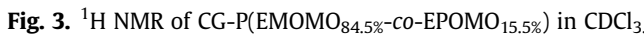

linker to form an adhesive with the catechol-containing polyoxetane and lap shear test was conducted to measure the bonding strength of the resulting adhesives. A 3:1 catechol/ $/ \mathrm{FeCl}_{3}$ ratio was employed in the adhesion process since it was speculated that under this ratio $\mathrm{Fe}^{3+}$ might form tris-complex with catechol and result in efficient cross-linking.

The results of lap shear tests showed that $\mathrm{FeCl}_{3}$ was effective in improving the adhesive strength of catechol-containing polyoxetanes, as shown in Fig. 4. For instance, without the addition of $\mathrm{FeCl}_{3}$, the adhesive strength of CG-P(EMOMO $\left.{ }_{84.5 \%-C o-E P O M O}{ }_{15.5 \%}\right)$ on stainless steel was only around $1.40 \mathrm{MPa}$. This number increased three times upon addition of $\mathrm{FeCl}_{3}$ to an average of $4.87 \mathrm{MPa}$ with the maximum up to $5.59 \mathrm{MPa}$. This result is consistent with the previous reports showing that addition of $\mathrm{Fe}^{3+}$ greatly enhances the mechanical properties of mussel-inspired materials [24,25].

The relationship between bonding strength and the content of catechols in the polymers was investigated using stainless steel as the substrate and the results are illustrated in Fig. 5. Best adhesion strength was achieved using polyoxetanes containing $15.5 \mathrm{~mol} \%$ catechol moiety. Although it is generally accepted that higher catechol content does not always leads to better adhesion strength, we noticed that the optimal catechol moiety content was obviously lower that other artificial mussel-inspired adhesives. For instance, although no optimal catechol content was given, for a polysiloxanebased adhesive polymer, the polymer containing $20 \mathrm{~mol} \%$ catechol exhibit better bonding behavior than that containing $15 \mathrm{~mol} \%$ catechol [14]. The optimal catechol content for best adhesive strength was $33 \mathrm{~mol} \%$ for catechol containing polystyrene type adhesives [22].

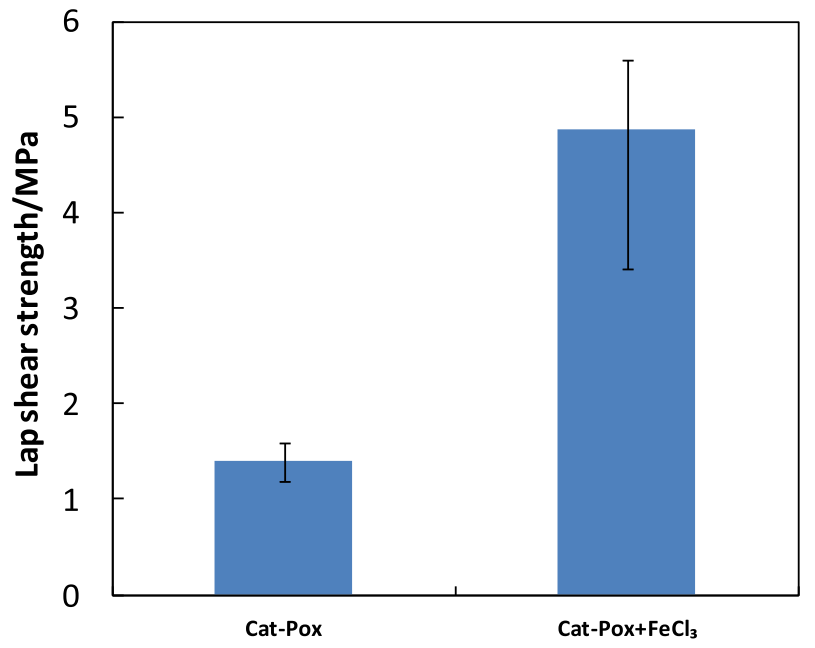

Fig. 4. Results of lap shear test using stainless steel as the substrate, where Cat-Pox refer to $\mathrm{CG}-\mathrm{P}\left(\mathrm{EMOMO}_{84.5 \%}\right.$-Co-EPOMO $\left.{ }_{15.5 \%}\right)$. 


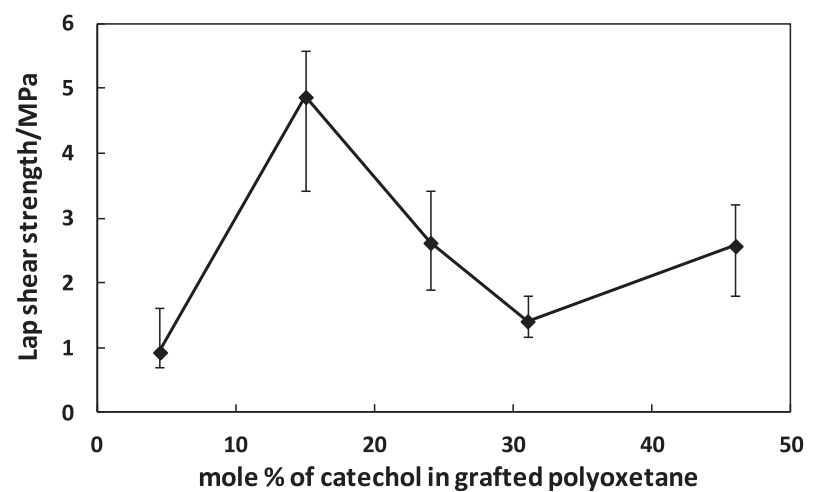

Fig. 5. Lap shear strength of $\mathrm{CG}-\mathrm{P}\left(\mathrm{EMOMO}_{\mathrm{x}}-\mathrm{Co}-\mathrm{EPOMO}_{\mathrm{y}}\right)$ on stainless steel as a function of the content of catechol.

Based on these results, we examined the reason for lower catechol content requirement to achieve better adhesive strength of catechol-containing polyoxetanes. We notice that the catechol might not be the only group that has coordination ability in our polyoxetane-based adhesive, and the triazole group formed via CuAAC could also form networks by forming triazole-metal complex [26,27], which might also contributes to the enhancement of the cohesive strength and adhesive strength. Also, the triazole group is structurally similar to the imidazole moiety in histidine, another important amino acid moiety in mfps that has the coordination ability $[28,29]$. Thus we speculated that one possible reason for lower catechol content requirement to achieve excellent bonding strength in our case is the coordination ability of triazole groups towards $\mathrm{Fe}^{3+}$. To test the speculation, a polyoxetane grafted with alkyl chains via CuAAC was synthesized (Supplementary Information, Scheme S3) and tested for its bonding strength in the presence of $\mathrm{FeCl}_{3}$. The bonding strength of catechol-free polyoxetanes bearing triazole groups is three-times stronger than that of unmodified polyoxetanes, as shown in Fig. 6, which supports our hypothesis. To the best of our knowledge, the synergy effect of catechol and triazole groups to improve the adhesive properties of mussel-inspired adhesives has not been reported.

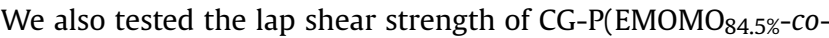
$\mathrm{EPOMO}_{15.5 \%}$ ) on different substrates using $\mathrm{FeCl}_{3}$ as the cross-linker (Fig.7). As expected, the adhesive showed highest bonding on metal substrates because of the high affinity of catechols to metal. The

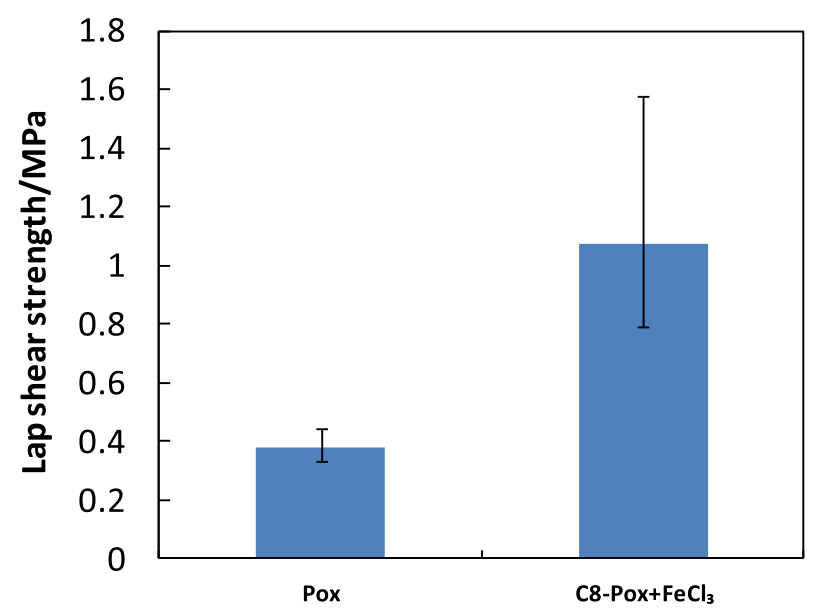

Fig. 6. Results of lap shear test using stainless steel as the substrate, where Pox refers to a polyoxetane without triazole groups, C8-Pox refers to $\mathrm{P}\left(\mathrm{EMOMO}_{85.5 \%}-\mathrm{CO}\right.$ $\mathrm{EPOMO}_{15.5 \%}$ ) grafted with octyl groups via triazole moiety. Both polymers have similar molecular weight.

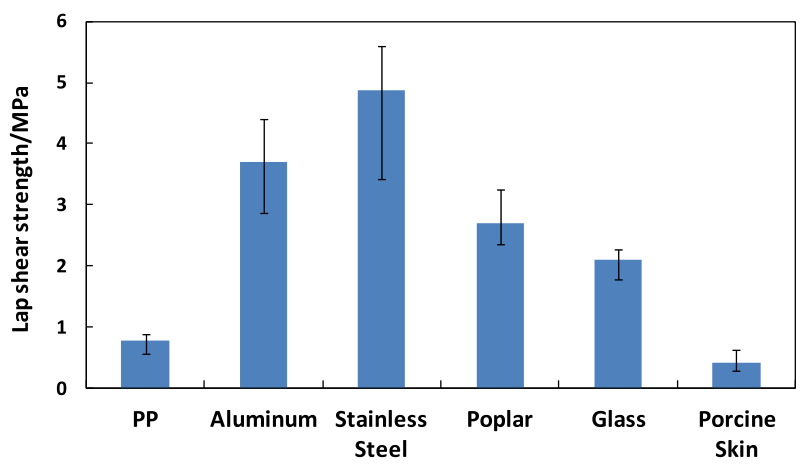

Fig. 7. Lap shear strength of CG-P(EMOMO84.5\%-co-EPOMO15.5\%) on different substrates.

average lap shear strength was 4.87 MPa and 3.70 MPa for stainless steel and aluminum respectively. The adhesive also performed well on poplar (2.69 MPa) and glass substrates (2.10 MPa). The bonding strength for polypropylene (PP) substrates was $0.77 \mathrm{MPa}$. Porcine skin, which is similar to human tissues, was bonded together with an average strength of $0.41 \mathrm{MPa}$. Overall, the performance of this mussel-inspired polymer is comparable to previously reported mussel-inspired adhesives. For example, a synthetic polypeptide mimic of mussel adhesive developed by Deming's group displayed a bonding strength of $2.8 \pm 0.7 \mathrm{MPa}$ on steel, $4.1 \pm 0.7 \mathrm{MPa}$ on aluminum, $2.3 \pm 0.3 \mathrm{MPa}$ on glass, lower than $0.1 \mathrm{MPa}$ on polyethylene [30]. The poly[(3,4-dihydroxystyrene)-co-styrene] adhesive bonded sanded steel at $5 \pm 1 \mathrm{MPa}$, aluminum at $7 \pm 1 \mathrm{MPa}$, red oak at $10 \pm 1 \mathrm{MPa}$ and polytetrafluorethylene at $0.4 \pm 0.1 \mathrm{MPa}$ [22]. Adhesion strength on porcine skin is commonly below $0.1 \mathrm{MPa}$ using PEG-based adhesives [31]. However, the comparison must be done cautiously in view of the different testing methods used.

Although at current stage, the catechol-containing polyoxetane we have synthesized is not water soluble so it is not applicable to test its biocompatibility, it could be converted into a water-soluble polymer by grafting PEG side chains onto its backbone, as reported by Yang and coworkers [13]. That will provide us an opportunity to test its biocompatibility. It is our next goal.

\section{Conclusions}

In conclusion, catechol-containing polyoxetane adhesive polymers were synthesized as alternatives to catechol-modified PEGs. Catechols were grafted onto polyoxetanes at various composition ratios via $\mathrm{Cu}(\mathrm{I})$-catalyzed click chemistry in an efficient manner. The adhesive showed a strong adhesion to a variety of substrates when $\mathrm{FeCl}_{3}$ was used as the cross-linker, with the maximum of bonding strength when the molar percent of catechol was around $15.5 \%$. Besides the catechols, the triazoles formed via click reaction might also contribute to the adhesion. Our work demonstrated that the polyoxetane is an adjustable platform for strong musselinspired adhesive design. Although the curing method used in the current experiments is not applicable in biomedical situations, the polymers could be further modified to be more suitable for biomedical use. The synthesis of a water-soluble adhesive polymer based on polyoxetane that is more suitable for biomedical use is currently underway in our laboratory. We believe that the biocompatibility and versatility of the polyoxetane backbone will eventually make it possible to be used for biomedical applications.

\section{Notes}

The authors declare no competing financial interest. 


\section{Acknowledgment}

The authors thanks the financial support from the "100 Talents" program from the Chinese Academy of Sciences.

\section{Appendix A. Supplementary data}

Supplementary data related to this article can be found at http:// dx.doi.org/10.1016/j.polymer.2014.01.028.

\section{References}

[1] Waite JH, Andersen SO. Biochim Biophys Acta (BBA) - Gen Subj 1978;541: 107-14.

[2] Waite JH, Tanzer ML. Science 1981;212:1038-40.

[3] Waite JH. Int J Adhes Adhes 1987;7:9-14.

[4] Lee BP, Dalsin JL, Messersmith PB. Biomacromolecules 2002:3:1038-47.

[5] Sean AB, Marsha R-J, Bruce PL, Phillip BM. Biomed Mater 2007;2:203.

[6] Brubaker CE, Kissler H, Wang L-J, Kaufman DB, Messersmith PB. Biomaterials 2010;31:420-7.

[7] Vreeland V, Waite JH, Epstein L. J Phycol 1998:34:1-8.

[8] Ye L, Feng Z-g, Su Y-f, Wu F, Chen S, Wang G-q. Polym Int 2005;54:1440-8.

[9] Makal U, Uilk J, Kurt P, Cooke RS, Wynne KJ. Polymer 2005;46:2522-30.

[10] Makal U, Wood L, Ohman DE, Wynne KJ. Biomaterials 2006;27:1316-26.

[11] Kurt P, Wynne KJ. Macromolecules 2007;40:9537-43.
[12] Zolotarskaya OY, Wagner AF, Beckta JM, Valerie K, Wynne KJ, Yang H. Mol Pharm 2012:9:3403-8.

[13] Zolotarskaya OY, Yuan Q, Wynne KJ, Yang H. Macromolecules 2013;46:63-71.

[14] Heo J, Kang T, Jang SG, Hwang DS, Spruell JM, Killops KL, et al. J Am Chem Soc 2012;134:20139-45.

[15] Goldmann AS, Schödel C, Walther A, Yuan J, Loos K, Müller AHE. Macromo Rapid Commun 2010;31:1608-15.

[16] Meldal M. Macromol Rapid Commun 2008;29:1016-51.

[17] Crivello JV, Sasaki H. J Macromol Sci Pure Appl Chem 1993;30:189-206.

[18] Nicolaou KC, Lister T, Denton RM, Gelin CF. Tetrahedron 2008;64:4736-57.

[19] Saegusa T, Hashimoto Y, Matsumoto S-i. Macromolecules 1971;4:1-3.

20] Saegusa T, Fujii H, Kobayashi S, Ando H, Kawase R. Macromolecules 1973;6: 26-32.

[21] Takeuchi D, Aida T. Macromolecules 1996;29:8096-100.

[22] Matos-Pérez CR, White JD, Wilker JJ. J Am Chem Soc 2012;134:9498-505.

[23] Monahan J, Wilker JJ. Chem Commun; 2003:1672-3.

[24] Podsiadlo P, Liu Z, Paterson D, Messersmith PB, Kotov NA. Adv Mater 2007;19: 949-55.

[25] Holten-Andersen N, Harrington MJ, Birkedal H, Lee BP, Messersmith PB Lee KYC, et al. Proc Natl Acad Sci U S A 2011:108:2651-5.

[26] Díaz DD, Punna S, Holzer P, McPherson AK, Sharpless KB, Fokin VV, et al J Polym Sci Part A Polym Chem 2004;42:4392-403.

27] Liu Y, Díaz DD, Accurso AA, Sharpless KB, Fokin VV, Finn MG. J Polym Sci Part A Polym Chem 2007;45:5182-9.

[28] Coyne KJ, Qin X-X, Waite JH. Science 1997;277:1830-2.

[29] Fullenkamp DE, He L, Barrett DG, Burghardt WR, Messersmith PB. Macromolecules 2013:46:1167-74.

[30] Yu M, Deming TJ. Macromolecules 1998;31:4739-45.

[31] Brubaker CE, Messersmith PB. Biomacromolecules 2011;12:4326-34. 